\title{
DNA microarray analysis of the gene expression profile of kidney tissue in a type 2 diabetic rat model
}

\author{
ZHENG SHEN $^{1}$, SHUYUN ZHANG ${ }^{2}$, CHAO CHUN ZOU $^{1}$, WEI ZHONG GU ${ }^{1}$ and SHI QIANG SHANG ${ }^{1}$ \\ ${ }^{1}$ Department of Medicine, The Children's Hospital of Zhejiang University, School of Medicine and Zhejiang Key Laboratory \\ for Diagnosis and Therapy of Neonatal Diseases; ${ }^{2}$ Hangzhou Sanitarium of PLA, Hangzhou, P.R. China
}

Received June 9, 2010; Accepted September 10, 2010

DOI: $10.3892 / \mathrm{mmr} .2010 .367$

\begin{abstract}
The aim of this study was to determine differences in the gene expression profile of kidney tissue from type 2 diabetes mellitus (T2D) and control rats using DNA microarray analysis. Total RNA was extracted from the kidney tissue of the T2D and control rats using the original single step method. cDNA retro-transcribed from an equal quantity of mRNA was labeled with $\mathrm{Cy} 5$ and $\mathrm{Cy} 3$ fluorescence and served as the probes. The mixed probes were hybridized to a DNA microarray. Fluorescence signals were scanned by an ScanArray 4000 laser scanner and further analyzed by QuantArray software. Apoptotic cells were detected in situ using the Roche TUNEL assay. Serum glucose, ApoAI, ApoB, ApoA1/ApoB, cholesterol and triglyceride levels were significantly higher in the T2D rats than in the controls, but there were no significant differences in serum insulin. When the kidney tissue was screened using the DNA microarray, differential expression was found for 41 genes. Five genes in the T2D rats were upregulated by 2-fold compared to the control rats, while 36 genes were down-regulated by 0.5 -fold. Moreover, in the renal tubular epithelial cells, there was a significantly greater number of TUNEL-positive cells in the T2D group than in the control group. A total of 41 genes are associated with the occurrence and development of T2D and diabetic nephropathy. The present study suggests that examining differences in gene expression profiles is of benefit to the diagnosis, treatment and prevention of $\mathrm{T} 2 \mathrm{D}$, diabetic nephropathy and other T2D complications.
\end{abstract}

\section{Introduction}

Type 2 diabetes mellitus (T2D) is a multi-gene disease caused by a combination of genetic and environmental factors, and has a strong heterogeneity. Diabetic nephropathy (DN), a

Correspondence to: Professor Shi Qiang Shang, The Children's Hospital of Zhejiang University School of Medicine, 57 Zhugan Xiang, Hangzhou 310003, P.R. China

E-mail: shenzheng@tom.com

Key words: type 2 diabetes mellitus, diabetic nephropathy, DNA microarray, kidney tissue, TdT-mediated dUTP nick end labeling microvascular complication of $\mathrm{T} 2 \mathrm{D}$, is the most serious and most common chronic complication. Five to ten percent of T2D patients develop DN, and it is a leading cause of mortality in patients with T2D. In Europe, the US and other developed countries, DN has become the main cause of the occurrence of end-stage renal disease $(1,2)$. In China, diabetic kidney disease-induced renal failure accounts for $15 \%$ of all renal failure cases. The molecular mechanisms of the causes of DN remain unclear due to their complexity.

In recent years, the application of molecular biology technology has contributed to significant progress in T2D research. An increasing number of DNA microarray methods are currently being applied in the study of the gene expression of T2D. Parallel analysis using a DNA microarray to detect differentially expressed genes in different specimens is a great improvement over traditional methods, in which the expression of only a single or several genes was observable with each test.

In the present study, differences between the gene expression patterns in the kidney tissues of T2D and control rats were investigated in order to explore T2D-associated gene clusters and their role in the occurrence and development of T2DN. This may aid in a comprehesive understanding of the molecular mechanisms of T2DN, and in the identification of molecular markers and target genes for the clinical diagnosis, prevention, prediction of susceptibility and treatment of T2DN and $\mathrm{T} 2 \mathrm{D}$.

\section{Materials and methods}

Animals. The Licensing Committee of Zhejiang University approved the experiments undertaken. Two-week-old pathogenfree inbred female SD rats $(n=15, \sim 160 \mathrm{~g})$ were obtained from the Animal Research Center of Zhejiang University. All rats were maintained at the Zhejiang University Animal Care Facility under a 12-h light/dark cycle. The rats were randomly divided into two groups: the T2D model group and the control group. The T2D rats $(n=10)$ were fed a high-lipid and high-glucose diet (10\% lard, 20\% sucrose, 5\% cholesterol and $65 \%$ conventional components) for 4 months, and were intraperitoneally injected with $25 \mathrm{mg} / \mathrm{kg}$ streptozotocin (STZ; Sigma, USA) ( $0.25 \%$ concentration, $\mathrm{pH} 4.2,0.1 \mathrm{~mol} / \mathrm{l}$ citrate buffer). Only 5 rats developed T2D (fasting plasma glucose $>7.8 \mathrm{mmol} / \mathrm{l}$ ) after 2 weeks of STZ injection. The control 
group rats $(n=5)$ were fed conventional chow and were intraperitoneally injected with citrate buffer.

At 22 weeks of age, the rats were sacrificed by cervical dislocation after being fasted for $4 \mathrm{~h}$. All experiments were carried out without the use of an anesthetic, as diethylether affects serum glucose concentrations. Whole blood and kidney tissues were collected after sacrifice. The kidney tissue was harvested and rapidly frozen in liquid $\mathrm{N}_{2}$, and all samples were stored at $-80^{\circ} \mathrm{C}$ until use.

Detection of glucose, insulin, total cholesterol, ApoA1, ApoB and triglyceride levels. Serum insulin was determined using a radioimmunoassay kit (Shanghai Institute of Biological Products). Serum glucose, total cholesterol and triglyceride levels were measured using an automatic biochemical analyzer (Hitachi 7060). ApoA1 and ApoB were detected using immune turbidimetry.

\section{Microarray analysis}

Isolation of total RNA. Total RNA from stocked kidney samples was extracted using TRIzol reagent (Invitrogen, USA) and purified using an RNeasy mini kit combined with an RNase-free DNase Digest set (Qiagen, Germany) for the degradation of genomic DNA in the total RNA samples. Total RNA extracted from 5 rats ( $5 \mu \mathrm{g}$ each) was then pooled into one sample in order to normalize individual differences, followed by gene expression analysis of the tissue by cDNA microarray (3). Total RNA extracted from the kidney tissue was stored at $-80^{\circ} \mathrm{C}$ until use.

Microarray preparation. A cDNA microarray with 4096 target cDNA clones was provided by United Gene Ltd. (Shanghai, China). These genes were amplified with PCR using universal primers and purified using a standard method (4). The obtained genes were dissolved in spotting buffer and then spotted on silylated slides (Telechem Inc., USA) by Cartesian 7500 Spotting Robotics (Cartesian Inc., USA). Each target gene was spotted twice, then the slides were hydrated for $2 \mathrm{~h}$ and dried for $0.5 \mathrm{~h}$ at room temperature (RT). The samples were cross-linked with UV light and treated with $0.2 \% \mathrm{SDS}, \mathrm{H}_{2} \mathrm{O}$ and $0.2 \% \mathrm{NaNBH}_{4}$ for $10 \mathrm{~min}$, respectively. The slides were lastly dried under cold conditions.

Probe preparation. The fluorescent-labeled cDNA probes were prepared through retro-transcription according to the method of Wang et al (5). The cDNA probes from the normal kidney tissue were labeled with Cy3-dCTP, while those from the T2D rat kidney tissue were labeled with Cy5-dCTP. Two groups of cDNA probes were mixed (Cy3-dCTP control + Cy5-dCTP T2D rats) and precipitated by ethanol, then dissolved in $13 \mu \mathrm{l}$ hybridization solution.

Hybridization and washing. Probes and the cDNA microarray were denatured in a $95^{\circ} \mathrm{C}$ bath for 2 min and $30 \mathrm{sec}$, respectively, then the probes were added to the cDNA microarray. Hybridization was performed in a sealed chamber at $42^{\circ} \mathrm{C}$ for $16-18 \mathrm{~h}$. Subsequently, the probes were washed in turn with solutions of $2 \mathrm{X} \mathrm{SSC}+0.2 \% \mathrm{SDS}, 0.1 \mathrm{X} \mathrm{SSC}+0.2 \%$ SDS and $0.1 \mathrm{X}$ SSC for $10 \mathrm{~min}$ each, and then dried at RT for $10 \mathrm{~min}$.

Fluorescent scanning and analysis. The cDNA microarray was read by the Scan Array 4000 laser scanner (Packard Biochip Technologies Inc., USA). The overall intensities of
Cy3 and Cy5 were normalized and corrected by a coefficient according to the normalization factor. The acquired image was further analyzed by QuantArray Software with a digital computer to obtain the intensities of the fluorescent signals and the $\mathrm{Cy} 3 / \mathrm{Cy} 5$ ratio. Data were gathered for an average of the two repeated spots. A gene was defined as being differentially expressed when i) the PCR results were satisfactory, ii) either the Cy3 or Cy5 signal value was $>600$, and iii) the absolute value of the Cy5/Cy3 natural logarithm was $>0.69$ (with a variation in gene expression $>2$-fold).

TdT-mediated dUTP nick end labeling (TUNEL). The apoptotic cells were detected in situ using the Roche TUNEL kit. The TUNEL method was performed to visualize the 3'-OH ends of DNA fragments in apoptotic cells according to the manufacturer's protocol. After xylene dewaxing, the sections were rinsed three times in DW for $5 \mathrm{~min}$ and then dipped in methanol containing $0.3 \% \mathrm{H}_{2} \mathrm{O}_{2}$ at $\mathrm{RT}$ for $30 \mathrm{~min}$ to inhibit endogenous peroxidase activity. After rinsing in PBS three times at RT for $5 \mathrm{~min}$, the sections were treated with proteinase $\mathrm{K}$ (Sigma, Germany) at $37^{\circ} \mathrm{C}$ for $8 \mathrm{~min}$. After rinsing in PBS three times at RT for $5 \mathrm{~min}$, the sections were soaked in the TdT buffer for $10 \mathrm{~min}$ and then incubated at $37^{\circ} \mathrm{C}$ for $60 \mathrm{~min}$ in a moist chamber with $50 \mu \mathrm{l}$ of the TdT buffer containing TdT (Roche, Germany). After rinsing in PBS three times at RT for $5 \mathrm{~min}$, the sections were placed in $50 \mu \mathrm{l}$ FITC (Roche) and then incubated at $37^{\circ} \mathrm{C}$ for $40 \mathrm{~min}$. After further rinsing in PBS three times for $5 \mathrm{~min}$, the sections were dipped in DAB (Roche) at RT for $3 \mathrm{~min}$, and the reaction was observed under a microscope. The reaction was terminated with DW, then the nuclei were counterstained with hematoxylin buffer.

Statistical analysis. Statistical analysis was carried out with SPSS 11.0 statistical software. Data are expressed as the mean \pm SD. Analysis of differences between the two groups was carried out using the Satterthwaite t-test.

\section{Results}

Body weight, serum glucose and insulin levels. The body weight of the T2D model rats administered a high-lipid and high-glucose diet for 4 months was significantly higher than that of the control rats $(\mathrm{P}=0.0084)$. There was no difference in serum glucose levels $(\mathrm{P}=0.8576)$. After the injection of $25 \mathrm{mg} / \mathrm{kg} \mathrm{STZ}$ for 2 weeks, hyperglycemia was noted in 5 of the $\mathrm{T} 2 \mathrm{D}$ rats. The serum glucose of these hyperglycemic rats was significantly increased $(\mathrm{P}=0.0023)$, while their weight was significantly decreased $(\mathrm{P}=0.018)$. The 5 hyperglycemic rats ingested more food and water than the control group rats. No similar changes in weight and serum glucose levels were found among the control group rats $(\mathrm{P}=0.6574$ and 0.2056$)$. No significant difference $(\mathrm{P}=0.994)$ was found between the serum insulin levels of the T2D and control groups (Table I). The levels of ApoAI, ApoB, ApoA1/ApoB, cholesterol and triglyceride in the T2D rats were significantly higher than those of the control group (Table II).

Purity of total RNA. The total RNA absorbance of A260/A280 was 1.8-2.0, demonstrating that the purity of the total RNA was satisfactory. Total RNA was not significantly degraded, 
Table I. Comparison of weight, serum glucose and insulin (mean \pm SD) in the T2D model and control groups.

\begin{tabular}{lccccc}
\hline & $\begin{array}{c}\text { Weight before } \\
\text { injection }(\mathrm{g})\end{array}$ & $\begin{array}{c}\text { Weight after } \\
\text { injection }(\mathrm{g})\end{array}$ & $\begin{array}{c}\text { Glucose before } \\
\text { injection }(\mathrm{mmol} / \mathrm{l})\end{array}$ & $\begin{array}{c}\text { Glucose after } \\
\text { injection }(\mathrm{mmol} / \mathrm{l})\end{array}$ & $\begin{array}{c}\text { Insulin after } \\
\text { injection }(\mu \mathrm{U} / \mathrm{ml})\end{array}$ \\
\hline T2D & $337.80 \pm 21.83$ & $297.20 \pm 21.44$ & $4.94 \pm 0.56$ & $18.19 \pm 7.23$ & $15.36 \pm 4.53$ \\
Control & $285.40 \pm 25.40$ & $293.80 \pm 31.92$ & $4.38 \pm 0.70$ & $5.17 \pm 1.08$ & $15.34 \pm 4.37$ \\
P-value & 0.0084 & 0.8489 & 0.8576 & 0.015 & 0.994 \\
\hline
\end{tabular}

Table II. Comparison of total cholesterol (CHO), ApoA1, ApoB and triglyceride (TG) levels in the T2D model and control groups.

\begin{tabular}{lccccc}
\hline & ApoA1 $(\mathrm{mg} / \mathrm{dl})$ & ApoB $(\mathrm{mg} / \mathrm{dl})$ & ApoA1/ApoB & CHO (mmol/l) & TG $(\mathrm{mmol} / \mathrm{l})$ \\
\hline T2D & $121.46 \pm 49.62$ & $265.24 \pm 16.21$ & $0.46 \pm 0.18$ & $21.12 \pm 9.43$ & $1.96 \pm 0.82$ \\
Control & $22.52 \pm 2.48$ & $35.80 \pm 4.27$ & $0.63 \pm 0.02$ & $2.17 \pm 0.08$ & $1.34 \pm 0.75$ \\
P-value & 0.0111 & 0.0115 & 0.03562 & 0.0109 & 0.04253 \\
\hline
\end{tabular}

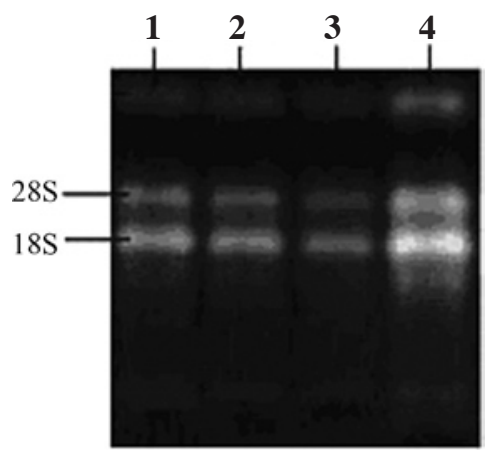

Figure 1. Gelose electrophoresis of the total RNA extracted from the kidney tissues. Lanes 1 and 2, total RNA of the kidney tissue of the control rats; 3 and 4, total RNA of the kidney tissue of the T2D rats.

as indicated by the presence of $28 \mathrm{~S}$ and $18 \mathrm{~S}$ RNA bands in the results of gelose electrophoresis (Fig. 1).

Hybridization signals on the gene chip. A scatter plot was plotted with the Cy3 and Cy5 fluorescent signal values, and displayed a quite disperse distribution pattern. Most of the spots were gathered around the $45^{\circ}$ diagonal line, with red spots representing the area where the signal intensities varied between 0.5 - and 2-fold compared to the control. Some yellow spots distributed beyond or far from the $45^{\circ}$ diagonal line indicated the existence of abnormal gene expression in the diabetic kidney. The signal intensities for the T2D group were 2 times stronger than those of the control.

Scanning analysis and gene expression patterns. cDNA probes labeled with $\mathrm{Cy} 3$ for the control and $\mathrm{Cy} 5$ for the diabetic kidney tissue groups were hybridized to a DNA microarray. Hybridization results were obtained in parallel by comparison of the sample gene expression patterns demonstrated. In the diabetic kidney tissue, 41 genes were found to have variations in expression $>2$-fold compared to the control. Among these
41 genes, 15 were not recorded in GenBank. The function of 29 genes remained undetermined. Five genes were up-regulated and 36 genes were down-regulated, as shown in Tables III and IV, respectively.

TUNEL-positive cells. Few TUNEL-positive cells were noted in each visual field in the renal tubules of the control group. In the T2D group, TUNEL-positive cells were scattered or clumped, were mostly located in epithelial cell tissues, and were significantly more numerous as compared to the control group ( $\mathrm{P}<0.01)$ (Table V; Fig. 2).

\section{Discussion}

Non-insulin-dependent diabetes mellitus (T2D) is a decompensatory endocrinopathy with a high incidence of $7 \%$. T2D results from a series of molecular changes and is caused by the abnormal expression of diabetes-associated genes (6). Therefore, it is necessary to investigate the kinetic changes in thousands of genes which make up the normal genome, rather than the study of one or several genes. Investigating gene expression may help understand the interrelation of genotype and phenotype. DNA microarray methods may be used to detect differences in gene expression in various specimens by parallel analysis on a large scale using just one procedure (7-16). Therefore, DNA microarray techniques have increasingly been applied to the study of gene expression. Detection of changes in gene expression in diabetes may reveal the cause of pathological changes and may also provide new targets for diagnosis and prevention.

In the present study, the DNA microarray technique was employed to analyze changes in gene expression patterns in a T2DN model. The expression levels of 41 genes in the diabetic kidney were were found to be increased or decreased. The functions of many of the genes were undetermined, or the genes were not yet registered in GenBank. Most of these genes were associated with glucose metabolism, fat metabolism and apoptosis-related enzymes. 
Table III. Genes with a differential expression $>2$ between the diabetic kidney and normal control tissues.

\begin{tabular}{lllc}
\hline Genbank-ID & UniGene & \multicolumn{1}{c}{ Definition } & Average ratio \\
\hline X86561 & Rn.5500 & Rat gene for $\alpha$-fibrinogen & 2.138 \\
AW915104 & Rn.6725 & EST346395 Rattus norvegicus cDNA, 5' end & 2.364 \\
BF282390 & Rn.9278 & EST446893 Rattus norvegicus cDNA, 3' end & 2.376 \\
B1292167 & Rn.19056 & UI-R-DN0-civ-c-07-0-UI.s1 Rattus norvegicus cDNA, 3' end & 2.108 \\
NM_053819 & Rn.25754 & Rattus norvegicus tissue inhibitor of metalloproteinase 1 (Timp-1), mRNA & 2.160 \\
\hline
\end{tabular}

Table IV. Genes with a differential expression $<0.5$ between the diabetic kidney and normal control tissues.

\begin{tabular}{|c|c|c|c|}
\hline Genbank-ID & UniGene & Definition & Average ratio \\
\hline AW915650 & Rn.17901 & EST346954 Rattus norvegicus cDNA, 5' end & 0.389 \\
\hline BE107033 & Rn.20198 & UI-R-BS1-ayp-a-04-0-UI.s1 Rattus norvegicus cDNA, 3' end & 0.399 \\
\hline J02585 & Rn.1023 & Rat liver stearyl-CoA desaturase mRNA, complete cds & 0.399 \\
\hline AA963985 & Rn.73529 & UI-R-C0-gs-e-04-0-UI.s1 Rattus norvegicus cDNA, 3' end & 0.446 \\
\hline NM_012533 & Rn.12780 & Rattus norvegicus carboxypeptidase B (Cpb), mRNA & 0.472 \\
\hline AA997888 & Rn.33114 & UI-R-C0-hu-h-12-0-UI.s1 Rattus norvegicus cDNA, $3^{\prime}$ end & 0.488 \\
\hline NM_012898 & Rn.32083 & Rattus norvegicus $\alpha 2$ HS-glycoprotein $\alpha 2$ (fetuin) (Ahsg), mRNA & 0.492 \\
\hline NM_012552 & Rn.6044 & Rattus norvegicus elastase 1 (Ela1), mRNA & 0.264 \\
\hline BI296422 & Rn.49412 & UI-R-CV2-cgr-a-06-0-UI.s1 Rattus norvegicus cDNA, 3' end & 0.324 \\
\hline AW916433 & Rn.11526 & EST347737 Rattus norvegicus cDNA, 5' end & 0.348 \\
\hline AI639370 & Rn.40539 & rx00135s Rattus norvegicus cDNA, 3' end & 0.364 \\
\hline BF415649 & Rn.62771 & UI-R-CA1-bkb-h-10-0-UI.s1 Rattus norvegicus cDNA, $3^{\prime}$ end & 0.377 \\
\hline AI548311 & Rn.43990 & UI-R-C3-tg-b-08-0-UI.s1 Rattus norvegicus cDNA, 3' end & 0.388 \\
\hline AA997888 & Rn.33114 & UI-R-C0-hu-h-12-0-UI.s1 Rattus norvegicus cDNA, 3' end & 0.395 \\
\hline BI296773 & Rn.16849 & UI-R-DK0-cfz-b-06-0-UI.s1 Rattus norvegicus cDNA, 3' end & 0.402 \\
\hline AW918368 & Rn.8749 & EST349672 Rattus norvegicus cDNA, 5' end & 0.407 \\
\hline BF555986 & Rn.15320 & UI-R-A1-dy-d-02-0-UI.r1 Rattus norvegicus cDNA, 5' end & 0.407 \\
\hline AA858817 & Rn.22047 & UI-R-A0-bn-h-04-0-UI.s1 Rattus norvegicus cDNA, 3' end & 0.411 \\
\hline NM_031537 & Rn.48721 & $\begin{array}{l}\text { Rattus norvegicus solute carrier family } 11 \text { member } 1 \\
\text { (natural resistance-associated macrophage protein 1), } \\
\text { see also D9Arb3 (Slc11a1), mRNA }\end{array}$ & 0.427 \\
\hline BF567520 & Rn.45035 & UI-R-BO0-agp-b-06-0-UI.r1 Rattus norvegicus cDNA, 5 ' end & 0.431 \\
\hline NM_022183 & Rn.55119 & Rattus norvegicus topoisomerase (DNA) II $\alpha$ (Top2a), mRNA & 0.432 \\
\hline BF398042 & Rn.12550 & UI-R-BS2-beg-f-04-0-UI.s1 Rattus norvegicus cDNA, 3 ' end & 0.433 \\
\hline BI299197 & Rn.3433 & UI-R-CV2-chs-d-03-0-UI.s1 Rattus norvegicus cDNA, 3' end & 0.435 \\
\hline BG378288 & Rn.22202 & UI-R-CV1-bvq-c-10-0-UI.s1 Rattus norvegicus cDNA, 3' end & 0.436 \\
\hline AW917734 & Rn.17053 & EST349038 Rattus norvegicus cDNA, 5' end & 0.443 \\
\hline NM_021752 & Rn.43867 & Rattus norvegicus apoptosis inhibitor 2 (Api2), mRNA & 0.446 \\
\hline NM_022297 & Rn.4241 & $\begin{array}{l}\text { Rattus norvegicus NG, NG dimethylarginine } \\
\text { dimethylaminohydrolase (Ddah1), mRNA }\end{array}$ & 0.447 \\
\hline BF566725 & Rn.54198 & UI-R-BJ0p-aff-a-06-0-UI.r1 Rattus norvegicus cDNA, 5' end & 0.448 \\
\hline BI295067 & Rn.25242 & UI-R-DK0-cef-d-10-0-UI.s1 Rattus norvegicus cDNA, 3' end & 0.453 \\
\hline NM_012503 & Rn.44300 & Rattus norvegicus asialoglycoprotein receptor 1 (hepatic lectin) (Asgr1), mRNA & 0.453 \\
\hline AI172457 & Rn.36857 & EST218468 Rattus norvegicus cDNA, 3' end & 0.460 \\
\hline AF016387 & Rn.8808 & Rattus norvegicus retinoid X receptor $\gamma(\mathrm{RXR} \gamma)$ mRNA, partial cds & 0.480 \\
\hline AA818602 & $\mathrm{Rn} .40378$ & UI-R-A0-bc-g-12-0-UI.s1 Rattus norvegicus cDNA, 3' end & 0.480 \\
\hline BI282211 & Rn.28004 & UI-R-CU0s-cbx-h-09-0-UI.s1 Rattus norvegicus cDNA, 3' end & 0.483 \\
\hline BG372437 & Rn.12364 & UI-R-CV1-bsc-g-03-0-UI.s1 Rattus norvegicus cDNA, 3' end & 0.492 \\
\hline $\mathrm{BI} 285816$ & Rn.11799 & UI-R-CX0s-ccv-b-12-0-UI.s1 Rattus norvegicus cDNA, $3^{\prime}$ end & 0.494 \\
\hline
\end{tabular}


Table V. Changes in apoptosis noted in the renal tissues of the T2D and control groups.

\begin{tabular}{lccc}
\hline Group & Slice no. & $\begin{array}{c}\text { No. of apoptotic cells } \\
\text { in a single field }\end{array}$ & P-value \\
\hline T2D & 20 & $11.18 \pm 5.32$ & $<0.01$ \\
Control & 20 & $2.56 \pm 0.65$ & \\
\hline
\end{tabular}

The $\alpha$-fibrinogen gene was one of the genes up-regulated in the kidney tissue of the T2D rats. In conjunction with increased blood glucose in T2D, the glycosylation level of blood fibrinogen increases significantly. This abnormal glycosylation reduces the glycosylation sensitivity of the blood fibrinogen fibrinolysis enzyme, which increases blood fibrinogen and creates erythrocyte aggregation. These changes easily lead to peripheral microvascular disease and induce DN (17).

Matrix metalloproteinase inhibitor gene 1 (Timp-1) was also found to be up-regulated in the kidney tissue of the T2D rats, consistent with a report by Suzuki et al (18), which showed that the expression of the Timp-1 gene was up-regulated in renal parenchymal and infiltrating cells in patients with ND. TIMP-1 is thought to play a role in resistance to lymphocyte-mediated apoptosis in vivo by decreasing the activity of NF-кB (19). Hence, the overexpression of Timp-1 in the kidneys of T2D rats may be an emergency response to resistance to tissue damage caused by increased blood glucose.

Wang et al $(20,21)$ reported that the retinoid $X$ receptor (Rxr) gene located on chromosome lq21-lq23 is among the best replicated regions with linkage to T2D in genome-wide scans. RXR is a member of the steroid/thyroid superfamily of nuclear receptors, and is likely to play a role in both glucose and lipid metabolism. RXR forms heterodimers or homodimers with a variety of nuclear receptors, including peroxisome-proliferator-activated receptors (PPARs) $\alpha$ and $\gamma$, thyroid hormone receptors and vitamin-D receptors, and subsequently alters insulin secretion and T2D susceptibility. Hence, a decrease in $R x r$ gene expression results in the disruption of glucose and lipid metabolism. In the present study, the RXR protein was also down-regulated in the T2D rats, which may have led to abnormal levels of cholesterol, triglycerides, apolipoprotein A and apolipoprotein B.

Stearyl-CoA desaturase (SCD), the terminal component of the SCD system, is a key enzyme involved in the synthesis of unsaturated fatty acids. It catalyzes the insertion of a double bond between carbons 9 and 10 in a spectrum of fatty stearyl-CoA substrates. When the activity of SCD is decreased, the ratio of saturated fatty acids and unsaturated fatty acids is altered. The abnormal alteration of this ratio has been shown to play a role in several physiological and disease states. In this study, we found that the activity of SCD was down-regulated in T2D rats, similar to reports by Waters and Ntambi (22) and Ntambi (23).

It has been demonstrated that the activity of topoisomerase II (Topo II) is rapidly decreased in T2D rats, which means that the enzyme may be related to islet cell destruction.
$\mathbf{A}$

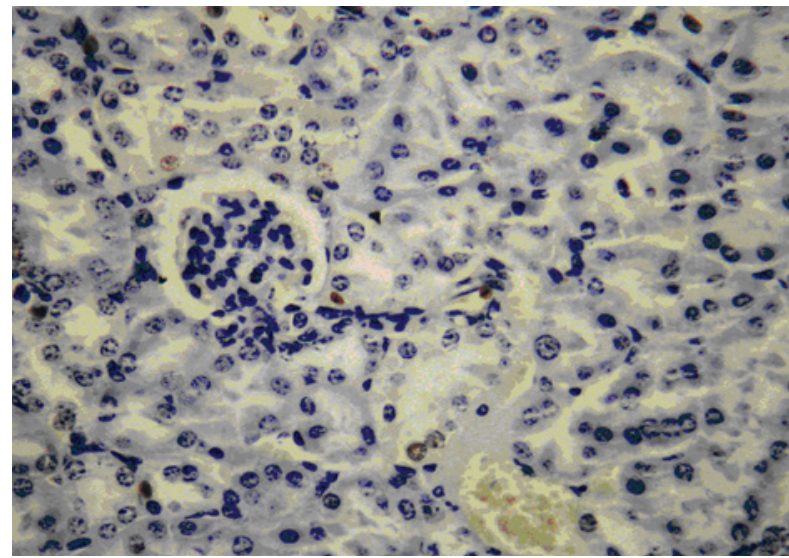

B

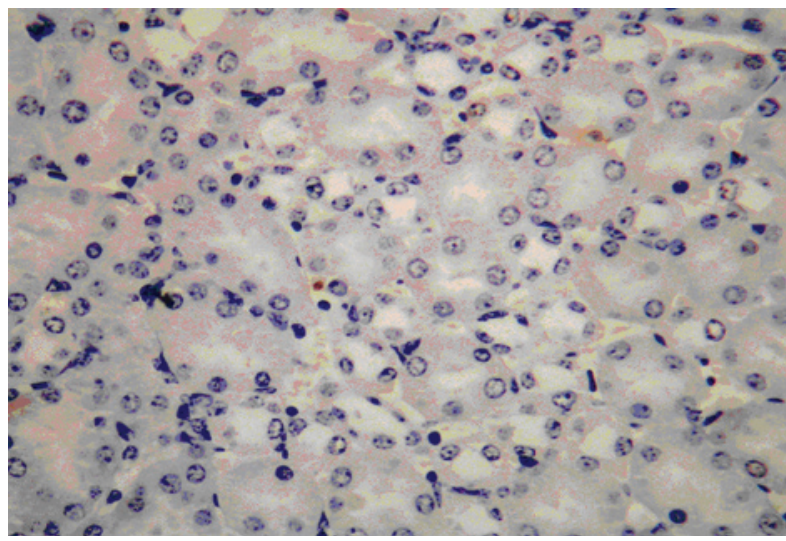

Figure 2. (A) TUNEL markers of apoptosis in renal tissue from T2D rats (B) TUNEL markers of apoptosis in renal tissue from control rats. Apoptotic cells are stained brown and the nuclei of cells blue; magnification x100.

Janik et al (24) reported that Topo II expression levels were obviously down-regulated in T2D rats, and produced irreversible DNA strand breakage during DNA replication or RNA transcription. In the present study, Topo II expression was similarly down-regulated.

Carboxypeptidase $\mathrm{B}$, which is present in the insulin secretion pathway, is an exocrine peptide protease containing zinc. It is closely related to insulin processing and is an indispensable protease that activates proinsulin to insulin. Hence, the activation and stability of carboxypeptidase B is an important parameter for proinsulin activation. In the present study, carboxypeptidase $B$ was down-regulated in the T2D rats, as in studies reported by Fricker et al (25) and Sanchez et al (26). This may be associated with a decreased proinsulin to insulin conversion.

The Apoptosis inhibitor 2 gene was also found to be downregulated. This implies that the occurrence and development of T2D is related to an impaired dynamic balance of cell proliferation and apoptosis. Hence, there is uncontrolled apoptosis in T2D, which is related to islet $\beta$ cell damage. Moreover, we found that the apoptosis rate of renal tubular epithelial cells in the T2D group was significantly higher compared to the control group, as similarly reported by Oritiz et al (27). We suggest that the expression of apoptosis-regulating genes is altered by metabolic disorders resulting from high-blood glucose levels, which increases apoptosis. Thus, the incidence of $\mathrm{DN}$ is related to apoptosis. 
The application of the DNA microarray technique is a revolutionary research method in the life sciences, and has great potential use for the discovery of novel type 2 diabetes-related genes. The present study demonstrates that the detection of differences in gene expression between diabetic and normal kidney tissue using DNA microarray methods may provide novel prospects for the diagnosis, therapy and prevention of human T2D, DN and other complications.

\section{Acknowledgements}

The authors thank Professor Kaixian Qian for the helpful discussions and review of the initial manuscript, and Qingfeng Yan and Kewen Jiang for providing technical assistance and comments related to the study. This study was supported by the Family Planning Commission of Zhejiang Province (grant no. 20085901) and the Education Commission of Zhejiang Province (grant no. Y200804085).

\section{References}

1. Merta M, Reiterova J and Rysara R: Genetics of diabetic nephropathy. Nephrol Dial Transplant 18: 24-25, 2003.

2. Harvey JN: Trends in the prevalence of diabetic nephropathy in type 1 and type 2 diabetes. Curr Opin Nephrol Hypertens 12: $317-322,2003$

3. Hayashi Y, Iida S, Sato Y, Nakaya A, Sawada A, Kaji N, Kamiya H, Baba Y and Harashima H: DNA microarray analysis of type 2 diabetes-related genes co-regulated between white blood cells and livers of diabetic Otsuka Long-Evans Tokushima Fatty (OLETF) rats. Biol Pharm Bull 30: 763-771, 2007.

4. Qian AR, Di SM, Gao X, Zhang W, Tian ZC, Li JB, Hu LF, Yang PF, Yin DH and Shang P: cDNA microarray reveals the alterations of cytoskeleton-related genes in osteoblast under high magneto-gravitational environment. Acta Biochim Biophys Sin 41: 561-577, 2009.

5. Wang HM, Ma WL, Huang $\mathrm{H}$, Xiao WW, Wang Y and Zheng WL: DNA microarray probe preparation by gel isolation nested PCR. J Biochem Mol Biol 37: 356-361, 2004.

6. Xu SH, Mou HZ, Lu GQ, Zhu CH, Yang ZY, Gao YL, Lou HK, Liu XL, Chen Y and Yang W: Gene expression profile difference in high and low metastatic human ovarian cancer cell lines by gene chip. Chin Med J 115: 36-41, 2002.

7. Sreekumar R, Halvatsiotis P and Schimke JC: Gene expression profile in skeletal muscle of type 2 diabetes and the effect of insulin treatment. Diabetes 51: 1913-1920, 2002.

8. Zou TT, Selaru FM, Xu Y, Shustova V, Yin J, Mori Y, Shibata D, Sato F, Wang S, Olaru A, Deacu E, Liu TC, Abarham JM and Melzer SJ: Application of cDNA microarrays to generate a molecular taxonomy capable of distinguishing between colon cancer and normal colon. Oncogene 21: 4855-4862, 2002.

9. Lin YM, Furukawa Y, Tsunoda T, Yue CT, Yang KC and Nakamura Y: Molecular diagnosis of colorectal tumors by expression profiles of 50 genes expressed differentially in adenomas and carcinomas. Oncogene 21: 4120-4128, 2002.

10. Sepulveda AR, Tao H, Carloni E, Sepulveda J, Graham DY and Peterson LE: Screening of gene expression profiles in gastric epithelial cells induced by Helicobacter pylori using microarray analysis. Aliment Pharmacol Ther 16: 145-157, 2002.

11. Zhou Y, Gwadry FG, Reinhold WC, Miller LD, Smith LH, Scherf U, Liu ET, Kohn KW, Pommier Y and Weinstein JN: Transcriptional regulation of mitotic genes by camptothecininduced DNA damage: microarray analysis of dose- and time-dependent effects. Cancer Res 62: 1688-1695, 2002.
12. Iizaka M, Furukawa Y, Tsunoda T, Akashi H, Ogawa M and Nakamura Y: Expression profile analysis of colon cancer cells in response to sulindac or aspirin. Biochem Biophys Res Commun 292: 498-512, 2002.

13. Nguyen DV and Rocke DM: Tumor classification by partial least squares using microarray gene expression data. Bioinformatics 18: 39-50, 2002.

14. Nakeff A, Sahay N, Pisano M and Subramanian B: Painting with a molecular brush: genomic/proteomic interfacing to define the drug action profile of novel solid-tumor selective anticancer agents. Cytometry 47: 72-79, 2002.

15. Takahashi Y, Nagata T, Ishii Y, Ikarashi M, Ishikawa K and Asai S: Up-regulation of vitamin D3 up-regulated protein 1 gene in response to 5-fluorouracil in colon carcinoma SW620. Oncol Rep 9: 75-79, 2002.

16. Selaru FM, Xu Y, Yin J, Zou T, Liu TC, Mori Y, Abraham JM, Sato F, Wang S, Twigg C, Olaru A, Shustova V, Leytin A, Hytiroglou P, Shibata D, Harpaz N and Meltzer SJ: Artificial neural networks distinguish among subtypes of neoplastic colorectal lesions. Gastroenterology 122: 606-613, 2002.

17. Asakawa $\mathrm{H}$, Tokunaga $\mathrm{K}$ and Kawakami F: Elevation of fibrinogen and thrombin-antithrombin III complex levels of type 2 diabetes mellitus patients with retinopathy and nephropathy. J Diabetes Complications 14: 121-126, 2000.

18. Suzuki D, Miyazaki M, Jinde K, Koji T, Yagame M, Endoh M, Nomoto Y and Sakai H: In situ hybridization studies of matrix metalloproteinase-3, tissue inhibitor of metalloproteinase-1 and type IV collagen in diabetic nephropathy. Kidney Int 52: 111-119, 1997.

19. Mclennan SV, Martell SKY and Yue DK: Effects of mesangium glycation on matrix metalloproteinase activities: possible role in diabetic nephropathy. Diabetes 51: 2612-2618, 2002.

20. Wang H, Chu W, Swapan KD, Zheng Z, Hasstedt SJ and Elbein SC: Molecular screening and association studies of retinoid-related orphan receptor $\gamma$ (RORC): a positional and functional candidate for type 2 diabetes. Mol Genet Metab 79: 176-182, 2003.

21. Wang H, Chu W, Hemphill C, Hasstedt SJ and Elbein SC: Mutation screening and association of human retinoid $\mathrm{X}$ receptor $\gamma$ variation with lipid levels in familial type 2 diabetes. Mol Genet Metab 76: 14-22, 2002.

22. Waters KM and Ntambi JM: Insulin and dietary fructose induce stearoyl-CoA desaturase 1 gene expression in liver of diabetic mice. J Biol Chem 269: 27773-27777, 1994.

23. Ntambi JM: Regulation of stearoyl-CoA desaturase by polyunsaturated fatty acids and cholesterol. J Lipid Res 40: 1549-1556, 1999.

24. Janik JE, Miller LL, Korn EL, Stevens D, Curti BD, Smith JW II, Sznol M, Conlon KC, Sharfman W, Urba WJ, Gause BL and Longo DL: A prospective randomized phase II trial of GM-CSF priming to prevent topotecan-induced neutropenia in chemotherapy-naïve patients with malignant melanoma or renal cell carcinoma. Blood 97: 1942-1946, 2001.

25. Fricker LD, Berman YL, Leiter EH and Devi LA: Carboxypeptidase E activity is deficient in mice with the fat mutation. Effect on peptide processing. J Biol Chem 271: 30619-30624, 1996.

25. Sanchez JC, Converset V, Nolan A, Schmid G, Wang S, Heller M, Sennitt MV, Hochstrasser DF and Cawthorne MA: Effect of rosiglitazone on the differential expression of diabetesassociated proteins in pancreatic islets of C57BI/6 lep/lep mice. Mol Cell Proteomics 1: 509-516, 2002.

26. Oritiz A, Ziyadeh FN and Neilson EG: Expression of apoptosisregulated genes in renal proximal tubular epithelial cells exposed to high ambient glucose and in diabetic kidneys. J Investig Med 45: 50-56, 1997. 